\title{
Comparative Study Using Different Infrared Zones of the Solventless Activation of Organic Reactions
}

\author{
María Olivia Noguez Córdova ${ }^{1}$, Carlos I. Flores Ramírez ${ }^{1}$, Benjamín Velasco Bejarano ${ }^{1}$, \\ Gabriel A. Arroyo Razo ${ }^{1}$, Francisco J. Pérez Flores ${ }^{2}$, Vladimir Carranza Tellez ${ }^{3}$ and \\ René Miranda Ruvalcaba ${ }^{1, *}$
}

1 Department of Chemistry, Faculty of Superior Studies Cuautitlan, Field 1, Autonomous National University of Mexico, Av. May 1st s/n, Z. C. 54740, Cuautitlan Izcalli, State of Mexico, Mexico; E-Mails: olinoco@yahoo.com.mx (M.O.N.C.); alcor_zet@hotmail.com (C.I.F.R.); qfbbevebe@gmail.com (B.V.B.); garroyo@unam.mx (G.A.A.R.)

2 Mass Spectrometry Laboratory, Institute of Chemistry, Autonomous National University of Mexico, Outer City, University City, Z. C. 04510, Coyoacan, D. F., Mexico; E-Mail: japeflo10@hotmail.com

3 Mass Spectrometry Laboratory, Center of Chemistry, Institute of Sciences, Benemérita University of Puebla, Z. C. 72570, Puebla, Mexico; E-Mail: vcarrant@msn.com

* Author to whom correspondence should be addressed; E-Mail: mirruv@yahoo.com.mx; Tel./Fax: +52-555-623-2024.

Received: 18 October 2011; in revised form: 21 November 2011 / Accepted: 22 November 2011 / Published: 29 November 2011

\begin{abstract}
In this work, the results of a study comparing the use of irradiation from different regions of the infrared spectrum for the promotion of several organic reactions, are presented and discussed. This use of eco-conditions provides a green approach to chemical synthesis. A set of ten different organic reactions were evaluated, including the Knoevenagel, Hantzsch, Biginelli and Meldrum reactions. It is important to highlight the use of a commercial device that produces infrared irradiation in the near infrared region and its distribution by convection providing heating uniformity, significantly reducing reaction times, achieving good yields and proceeding in the absence of solvent. It is also worth noting that a variety of different reactions may be performed at the same time. Finally, the products obtained were identified using TLC, together with corresponding MS-data, complementarily in comparison of $\mathrm{NMR}{ }^{1} \mathrm{H}$ and ${ }^{13} \mathrm{C}$ data with literature information.
\end{abstract}


Keywords: solventless; comparative study; infrared irradiation; green approach

\section{Introduction}

In recent years there has been a concerted effort to introduce everybody involved with chemistry with the subject of the 12 green chemistry principles, both in the classroom and in the laboratory [1-7] In this sense the phrase "Green Chemistry" implies reaction optimization with respect to materials and energy usage, waste reduction from all sources, and overall cost reduction. In addition, minimization of toxicity and hazards as well as maximization of safety practices must be also considered.

In relation to the sixth principle of the Green Chemistry Protocol, heating by infrared irradiation has been around a long time, and consequently its many advantages have been applied to satisfy a wide range of academic and industrial processes. New applications arise continually that take advantage of this highly efficient, controllable and rapid response heat source. Consequently, and as a part of our main chemical research interests, our research group has published several green approaches to chemical synthesis using activation by infrared irradiation, mainly from middle wavelengths, for many organic transformations [8-10].

On the other hand, there is a commercial device, "Flavor Wave ${ }^{\circledR}$ " (Watts $1300 \mathrm{~W}$, Volteage $110 \mathrm{~V} / 120 \mathrm{~V}-60 \mathrm{~Hz} \mid 220 \mathrm{~V} / 240 \mathrm{~V}-60 \mathrm{~Hz}$ ), that combines near infrared irradiation with heat transfer by convection. This reduces heating times by increasing the efficiency and uniformity of the heating. The goal of this work is therefore a comparative study of various typical organic reactions using, on the one hand, middle wavelength infrared irradiation (vide supra) and, on the other and for the first time, near-infrared irradiation generated by a tungsten-halogen lamp (1.15-1.5 microns). Both reactions take place in the absence of solvent.

\section{Results and Discussion}

In Table 1 were summarized the results of a set of ten different reactions, as well as the corresponding reaction conditions. During the development of this work, the expected molecules were obtained using mainly as activating mode near infrared irradiation compared with middle wavelength infrared irradiation. For near infrared irradiation, it is worth noting the significantly reduced reaction times of this novel mode (to the half and even to a third, for example entries $\mathbf{g}$ and $\mathbf{h}$ ), in comparison with the results found in the literature [8-10] using middle wavelength infrared irradiation. It is also important to highlight the possibility of carrying out several different reactions at the same time due to the design of the container providing efficiency due to the heating uniformity provided by convection that allows placing of multiple reaction flasks.

In general, the advantages of infrared-assisted reactions lie not only in their higher speed, but also because of the fact that these reactions are energetically favored, in addition to being generally cleaner and more economical than using standard conditions such as a thermal heating mantle. In addition, when infrared-assisted reactions are carried out in the absence of a solvent, the reactions become "greener", offering environmentally friendly ways of practicing chemistry. 
Table 1. Near vs. middle infrared irradiation for the completion of organic reactions.

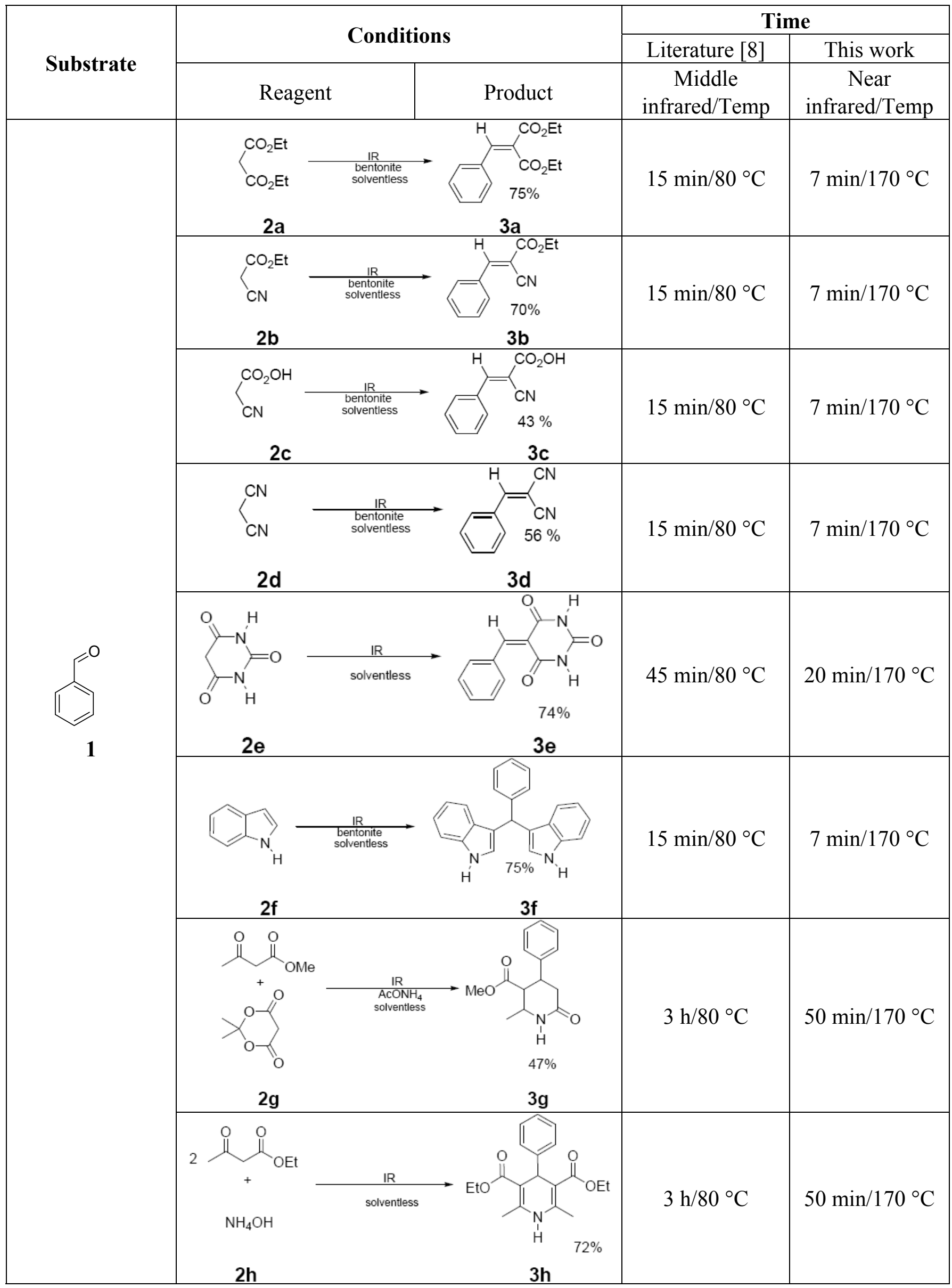


Table 1. Cont.

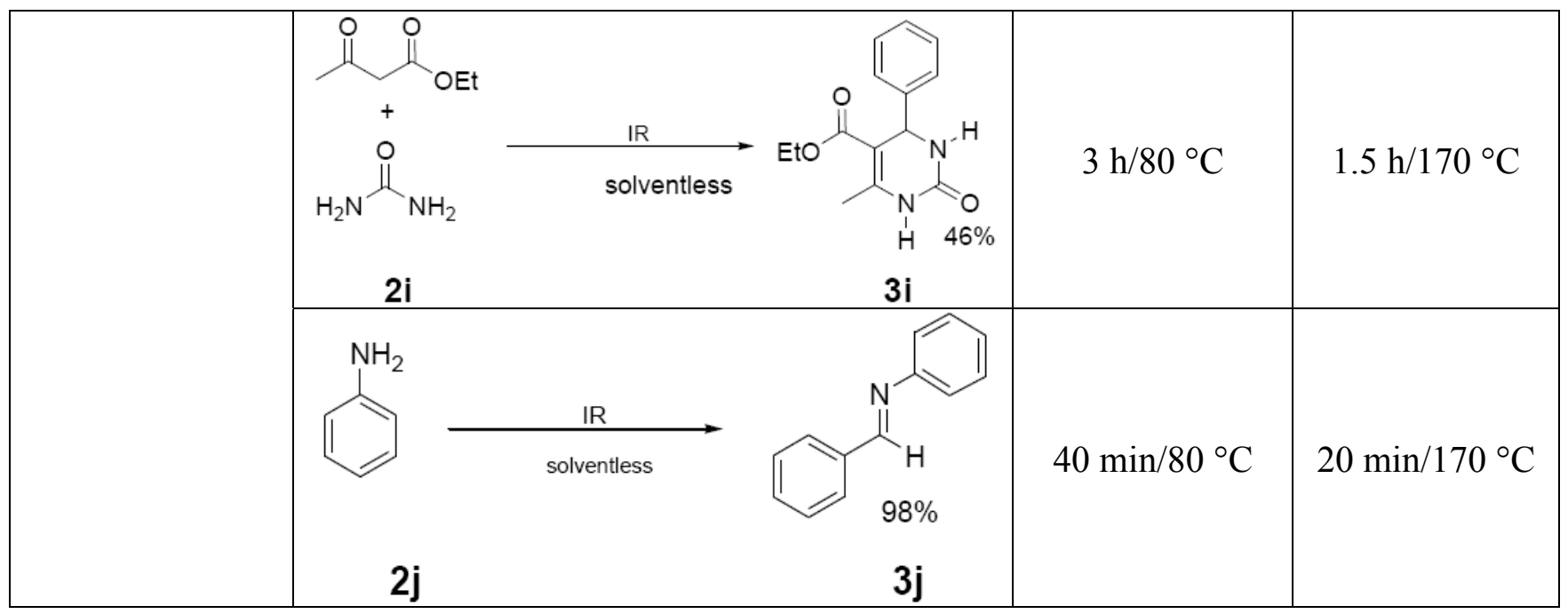

Furthermore, it is important to take into account interesting advantages resulting from the use of near infrared irradiation [11] as a new mode in chemical reactions; these include: the immediate response time for the heat source $(<1 \mathrm{~s})$, the efficient use of applied energy, favoring the product by convection due to the minimal amount of internal moving air, the long life time of the tungsten-halogen filament that is considered as a clean energy source with very low environmental impact (vide supra).

In regard to the identification of the molecules obtained $(\mathbf{3 a}-\mathbf{j})$, they were detected at the reaction using thin layer chromatography that monitored the disappearance of the substrate (1) and consequently detected the presence of $\mathbf{3 a}-\mathbf{j}$.

Once the products were purified, the corresponding (EIMS) data were obtained and compared with the literature [8-10] (Table 2). The characteristic peaks provide evidence for the presence of the target molecules; moreover, NMR data was also in agreement, by comparison with literature information [8], as it can see for example in three selected examples [12].

Table 2. Characteristic peaks for the target molecules, revealed by EIMS and compared with data reported in the literature.

\begin{tabular}{|c|c|c|}
\hline Compound & $m / z\left(\%\right.$ relative abundance) $\mathrm{M}^{+\bullet}$ & Others Peaks $m / z(\%$ relative abundance) \\
\hline $\mathbf{3 a}$ & $248(23)$ & $176(100), 172(13), 77(20)$ \\
\hline $\mathbf{3 b}$ & $201(39)$ & $129(99), 125(22), 77(18)$ \\
\hline $\mathbf{3 c}$ & $173(95)$ & $172(100), 156(8), 146(5), 128(23), 101(8)$ \\
\hline $\mathbf{3 d}$ & $154(100)$ & $127(75), 100(11)$ \\
\hline $\mathbf{3 e}$ & $216(63)$ & $215(100), 172(63), 145(7), 127(17), 102(26)$ \\
\hline $\mathbf{3 f}$ & $322(100)$ & $321(34), 245(52)$ \\
\hline $\mathbf{3 g}$ & $229(88)$ & $300(21), 284(25), 256(30), 252(100)$ \\
\hline $\mathbf{3 h}$ & $329(44)$ & $231(66), 187(39), 183(100)$ \\
\hline $\mathbf{3 i}$ & $260(27)$ & $105(100), 77(34)$ \\
\hline $\mathbf{3 j}$ & $181(63)$ & \\
\hline
\end{tabular}




\section{Experimental}

The benzaldehyde and other reactants used as substrates are commercially available (Sigma-Aldrich Chemical Co.) and were employed without further purification. The reactions were monitored by TLC, on percolated $(0.25 \mathrm{~mm})$ Merck silica-gel $60-\mathrm{F}_{254}$ aluminum sheets. Product visualization was carried out using a 254 and $365 \mathrm{~nm} \mathrm{UV} \mathrm{lamp,} \mathrm{I}_{2}$ or $\mathrm{CeSO}_{4} \cdot \mathrm{H}_{2} \mathrm{SO}_{4} 1 \%$. EIMS were acquired on a JEOL MStation JMS-700 mass spectrometer. EIMS was performed with a source temperature of $230{ }^{\circ} \mathrm{C}$, an ionization energy of $70 \mathrm{eV}$ and an ionization trap current of $300 \mu \mathrm{A}$. NMR experiments were carried out using a Varian Mercury-300 at $300 \mathrm{MHz}$ and $75 \mathrm{MHz}$ for hydrogen and carbon respectively, the solvents used were DMSO-d6 and $\mathrm{CDCl}_{3}$; TMS was employed as the internal reference. The middle infrared irradiation was performed using a Phillips IR lamp (375 W/220 V) integrated to an infrared reactor $^{8}$ designed by our research group, and validated by a wide number of applications. The Flavorwave Oven ${ }^{\circledR}$ uses a tungsten-halogen lamp which produces near infrared waves and complements heat distribution by convection.

General Method. (3a-j). A mixture of benzaldehyde and the corresponding reagent $(\mathbf{2} \mathbf{a}-\mathbf{j})$ ( $1 \mathrm{mmol}$ of each), were thoroughly mixed in a round-bottomed flask $(10 \mathrm{~mL})$. These mixtures were exposed to infrared irradiation (middle and near wavelengths), respectively. The corresponding reactions were monitored by TLC using the reported eluent (middle IR). Purification of the products was carried out by means of the methodology reported for each product [8].

\section{Conclusions}

Infrared irradiation from the near region and distributed by convention is offered as a very convenient mode to activate organic reactions. It is highly efficient, controllable and clean and opens the possibility of increasing the green approach to synthetic chemistry.

\section{Acknowledgments}

The authors acknowledge Daniela V. Sánchez Castro for technical assistance and UNAM-DGAPA-PAPIIT Project IN228010-3 and UNAM-FESC PACIVE GC-05 for funding this project.

\section{References and Notes}

1. Anastas, P.T.; Warner, J.C. Green Chemistry: Theory and Practice; Oxford University Press: New York, NY, USA, 1998.

2. Matlack, A.S. Introduction to Green Chemistry; Marcel Dekker; New York, NY, USA, 2001.

3. Lancaster, M. Green Chemistry: An Introductory Text; Royal Society of Chemistry: Cambridge, UK, 2002.

4. Hjeresen, D.L.; Schutt, D.L.; Boese, J.M. Green chemistry and education. J. Chem. Educ. 2000, $77,1543-1544$.

5. Collins, T.J. Introducing green chemistry in teaching and research. J. Chem. Educ. 1995, 72, 965-966. 
6. Arroyo, G.; Hernández, E.; Martínez, J.; Miranda, R.; Noguez, O.; Penieres, J.; Rivero, C.; Velasco, B.; Vilchis, M.; Gómez, C. Prácticas de Laboratorio de Química Orgánica Verde; Editorial Tecnológica de Costa Rica: Cartago, Costa Rica, 2010.

7. Miranda-Ruvalcaba, R.; Penieres-Carrillo, J.G.; Obaya-Valdivia, A.; Palma-Cruz, A.; Frontana-Uribe, B.; Nicolás-Vázquez, M.I.; Vargas-Rodríguez, Y.M.; Martínez, J.O.; Martín-Hernández, O.; Reyes-Sánchez, L.B.; et al. Química Verde Experimental; Universidad Nacional Autónoma de México (UNAM): Coyoacán, Distrito Federal, México, 2011.

8. Miranda, R.; Noguez, O.; Velasco, B.; Arroyo, G.; Penieres, G.; Martínez, O.; Delgado, F. Irradiación infrarroja una alternativa para la activación de reacciones y su contribución a la química verde. Educ. Quím. 2009, 20, 421-425 and references therein.

9. Noguez, M.O.; García, A.; Ibarra, C.; Cabrera, A.; Aceves, J.M.; Nicolás, M.I.; Miranda, R. Green synthesis of bis-biginelli esters, with vasodilatory effects, their mass spectrometric and physical studies. Trends Org. Chem. 2009, 13, 75-82.

10. Noguez, M.O.; Marcelino, V.; Rodríguez, H.; Martín, O.; Martínez, J.O.; Arroyo, G.A.; Pérez, F.J.; Suárez, M.; Miranda, R. Infrared assisted production of 3,4-Dihydro-2(1H)-pyridones in solvent-free conditions. Int. J. Mol. Sci. 2011, 12, 2641-2649.

11. Shortwave Electric Infrared the Facts. Copyright $($ ITW BGK Finishing Systems 05/03. Available online: http://www.bgk.com (accessed on 11 August 2011).

12. 3c ${ }^{1} \mathrm{H}$ NMR (300 MHz, DMSO-d $\left.6, \delta\right): 8.56(\mathrm{~s}, 1 \mathrm{H}, \mathrm{HC}=\mathrm{C}), 7.96\left(\mathrm{~d}, J=7.9 \mathrm{~Hz}, 2 \mathrm{H}, \mathrm{H}_{2,6}\right)$, 7.7-7.55 (m, 3H, $\left.\mathrm{H}_{3,4,5}\right)$; ${ }^{13} \mathrm{C}$ NMR (75 MHz, DMSO-d 6 , $\left.\delta\right): 162.0(\mathrm{HC}=\mathrm{C}), 134.8\left(\mathrm{C}_{4}\right), 131.9\left(\mathrm{C}_{1}\right)$, $131\left(\mathrm{C}_{3,5}\right), 130\left(\mathrm{C}_{2,6}\right), 114.4\left(\mathrm{~d},{ }^{3} J_{\mathrm{H}}{ }^{13} \mathrm{CN}=8.6 \mathrm{~Hz}, \mathrm{CN}_{\text {trans }}\right), 113.5\left(\mathrm{~d},{ }^{3} \mathrm{~J}_{\mathrm{H}}{ }^{13} \mathrm{CN}=14.4 \mathrm{~Hz}, \mathrm{CN}_{\text {cis }}\right)$, $82(\mathrm{HC}=\underline{\mathrm{C}})$.

3e ${ }^{1} \mathrm{H}$ NMR (300 MHz, DMSO-d 6 , $\left.\delta\right): 11.40$ (s, 1H, NH), $11.22(\mathrm{~S}, 1 \mathrm{H}, \mathrm{NH}), 8.35(\mathrm{~S}, 1 \mathrm{H}, \underline{\mathrm{HC}}=\mathrm{C})$, $8.13\left(\mathrm{~d}, J_{2,3}=J_{6,5} 7.1 \mathrm{~Hz}, 2 \mathrm{H}, \mathrm{H}_{2,6}\right), 7.44\left(\mathrm{~m}, 3 \mathrm{H}, \mathrm{H}_{3,4,5}\right) ;{ }^{13} \mathrm{C} \mathrm{NMR}\left(75 \mathrm{MHz}, \mathrm{DMSO}-\mathrm{d}_{6}, \delta\right)$ : $163.4\left(\mathrm{C}=\mathrm{O}_{\text {trans }}\right), 162.0\left(\mathrm{C}=\mathrm{O}_{\text {cis }}\right), 155.2(\mathrm{H} \underline{C}=\mathrm{C}), 150.6(\mathrm{HN} \underline{\mathrm{CONH}}), 133.6\left(\mathrm{C}_{2,6}\right), 133.1\left(\mathrm{C}_{4}\right) 132.5$ $\left(\mathrm{C}_{1}\right), 128.5\left(\mathrm{C}_{3,5}\right), 119.3(\mathrm{HC}=\underline{\mathrm{C}})$.

3g ${ }^{1} \mathrm{H}$ NMR (300 MHz, $\left.\mathrm{CDCl}_{3}, \delta\right): 7.22$ (Ar), $9.93(\mathrm{HN}), 2.94(3 \mathrm{H}), 4.28(4 \mathrm{H}), 2.33(7 \mathrm{H})$, $3.54\left(\mathrm{OCH}_{3}\right) ;{ }^{13} \mathrm{C} \mathrm{NMR}\left(75 \mathrm{MHz}, \mathrm{CDCl}_{3}, \delta\right): 170.4\left(\mathrm{C}_{2}\right), 37.9\left(\mathrm{C}_{3}\right), 31.3\left(\mathrm{C}_{4}\right), 105.1\left(\mathrm{C}_{5}\right)$, $149.3\left(\mathrm{C}_{6}\right), 18.9\left(\mathrm{C}_{7}\right), 167.6\left(\mathrm{C}_{8}\right), 51.8\left(\mathrm{C}_{9}\right), 143.2\left(\mathrm{C}_{10}\right), 127.2\left(\mathrm{C}_{11}\right), 129.3\left(\mathrm{C}_{12}\right), 126.0\left(\mathrm{C}_{13}\right)$, $129.3\left(\mathrm{C}_{14}\right), 127.2\left(\mathrm{C}_{15}\right)$.

(C) 2011 by the authors; licensee MDPI, Basel, Switzerland. This article is an open access article distributed under the terms and conditions of the Creative Commons Attribution license (http://creativecommons.org/licenses/by/3.0/). 